\title{
Supraphysiological oxytocin increases the transfer of immunoglobulins and other blood components to milk during lipopolysaccharide- and lipoteichoic acid-induced mastitis in dairy cows
}

\author{
Samantha K. Wall, ${ }^{\star} \dagger$ Olga Wellnitz, ${ }^{*}$ Lorenzo E. Hernández-Castellano, ${ }^{*}$ Amir Ahmadpour, ${ }^{*} \ddagger$ \\ and Rupert M. Bruckmaier*1 \\ *Veterinary Physiology, Vetsuisse Faculty University of Bern, 3001 Bern, Switzerland \\ †Graduate School for Cellular and Biomedical Science, University of Bern, 3012 Bern, Switzerland \\ ‡Department of Animal Science, Faculty of Agriculture, Bu-Ali Sina University, 65178-3313 Hamadan, I. R. Iran
}

\section{ABSTRACT}

Bacterial mastitis causes pathogen-dependent changes of the blood-milk barrier, and these changes can influence the differential transfer of blood components to milk. It is well known that gram-negative pathogens such as Escherichia coli can cause a greater activation of the immune system and thus a more comprehensive transfer of blood components including IgG than gram-positive pathogens such as Staphylococcus aureus. Supraphysiological doses of oxytocin (OT) have been shown to increase the permeability of the blood-milk barrier; however, the effect of OT during experimentally induced mastitis has not been investigated. Therefore, the objective of this study was to examine if intravenous administration of OT during lipopolysaccharide (LPS)- or lipoteichoic acid (LTA)induced mastitis could influence the transfer of blood components to milk. The hypothesis was that OT could induce a greater transfer of blood components during mastitis. Twenty-seven dairy cows were injected via the teat canal with LPS, LTA, or a saline control followed by an intravenous injection of OT $2 \mathrm{~h}$ following intramammary challenge. Milk samples were collected every half hour and analyzed for somatic cell count (SCC), $\mathrm{IgG}$, lactate dehydrogenase (LDH), and serum albumin (SA). Due to the chosen dosage of LPS and LTA, there was no difference in SCC between quarters challenged with only LPS or LTA. Quarters challenged with LPS and OT had a higher SCC and a greater transfer of $\mathrm{IgG}, \mathrm{LDH}$, and SA compared with quarters challenged with only LPS. Quarters challenged with LTA and OT had a greater transfer of IgG, LDH, and SA, whereas the SCC increase did not differ from quarters only treated with LTA. In quarters treated only with OT,

Received June 2, 2016.

Accepted July 14, 2016.

${ }^{1}$ Corresponding author: rupert.bruckmaier@vetsuisse.unibe.ch
SCC, LDH, and SA increased, but no difference was observed in $\mathrm{IgG}$ concentration from untreated control quarters. In conclusion, there are pathogen-specific changes in the blood-milk barrier and OT can induce a greater transfer of blood components to milk in both LPS- and LTA-induced mastitis. Oxytocin could have implications for use as a mastitis therapy, as there was an increased transfer of IgG into the milk.

Key words: mastitis, blood-milk barrier, endotoxin, oxytocin

\section{INTRODUCTION}

Mastitis is usually caused by bacterial pathogens invading the mammary gland and these bacteria cause a pathogen-specific activation of the immune system and influence permeability of the blood-milk barrier (Wellnitz and Bruckmaier, 2011). Clinical mastitis cases, such as quarters infected with the gram-negative pathogen Escherichia coli, have a greater transfer of various blood proteins including IgG, and a greater stimulation of the immune system. This is compared with subclinical mastitis, which is often associated with gram-positive pathogens such as Staphylococcus aureus (Bannerman et al., 2004; Wellnitz et al., 2013). These findings could relate to the mostly chronic infections associated with $S$. aureus, as infections with this bacterium generally do not induce a pronounced immune response that is mirrored by a moderate upregulation of pro-inflammatory cytokines in the mammary gland (Sutra and Poutrel, 1994; Wellnitz and Bruckmaier, 2011).

Bacteria have specific endotoxins embedded in the cell wall: LPS on E. coli and lipoteichoic acid (LTA) on $S$. aureus. Intramammary injection of these 2 proteins can be used to induce and mimic the inflammation that occurs during mastitis. When dosages of LPS and LTA are chosen to induce equal SCC increases, it has been shown that LPS can induce a greater transfer of blood- 
derived proteins to the milk than LTA (Wellnitz et al., 2013).

Oxytocin $(\mathbf{O T})$ is a hormone that causes contraction of myoepithelial cells surrounding the alveoli that leads to milk ejection. Exogenous OT administered in supraphysiological concentrations was previously shown to increase the permeability of the blood-milk barrier (Allen, 1990). The mechanism of action for OT is not fully understood, but it can be speculated that mammary epithelial tight junction integrity is compromised from the mechanical stress of inducing maximum alveolar contraction (Stelwagen and Singh, 2014).

Increased permeability of the blood-milk barrier is characterized by the appearance of blood constituents in milk because of the paracellular diffusion of blood and milk components during mastitis (Nguyen and Neville, 1998). These constituents include the proteins serum albumin (SA) and lactate dehydrogenase (LDH; Stelwagen et al., 1994; Lehmann et al., 2013; Wall et al., 2015) as markers, as well as immunoglobulins, which have functional properties during an intramammary immune response (Burton and Erskine, 2003).

The aim of the present study was to examine if intravenous OT administration at a supraphysiological dosage would influence the transfer of IgG and other markers of barrier integrity to milk during LPS- or LTA-induced mastitis. Furthermore, this may indicate a basis for the potential use of OT in mastitis therapy. The hypothesis was that OT induces a greater transfer of blood components, including IgG, that may have a functional role in the mammary immune response.

\section{MATERIALS AND METHODS}

\section{Animals}

All animal trials were approved by the Cantonal Committee of Animal Experiments, Fribourg, Switzerland, and all experimental procedures followed the Swiss law of animal protection. Twenty-seven dairy cows [Holstein $(\mathrm{n}=20)$, Swiss Fleckvieh $(\mathrm{n}=7)$ ] in mid-lactation (mean DIM $=199 \pm 22$ ) were enrolled. Parities of experimental cows ranged from 1 to 5 (average parity $=2$ ) and cows were producing $>15 \mathrm{~L}$ of milk/d (mean milk yield $=20.0 \pm 0.6$ ). All cows had a SCC $<200 \times 10^{3}$ cells $/ \mathrm{mL}$ in all 4 quarters during the $3 \mathrm{~d}$ before the experiment and showed no signs of clinical mastitis. Sterile milk samples for bacteriological culture were collected aseptically from all quarters and processed according to Hogan et al. (1999), and all cows were negative for mastitis-causing pathogens. Cows were housed at the Agroscope research station (Posieux, Switzerland) in straw and sawdust bedded tie-stalls for the duration of the experiment. Cows were fed roughage ad libitum and energy concentrate according to their individual production levels. Water was available ad libitum. Cows were machine milked twice daily at 0530 and $1600 \mathrm{~h}$.

\section{Experimental Procedures and Treatments}

The day before the experiment, jugular catheters (105 mm long, internal and external diameters of 1.9 and $2.4 \mathrm{~mm}, 13$ gauge, Vygon, Ecouten, France) were inserted and immediately flushed with $0.9 \%$ sterile saline and 5,000 IU of heparin (Laboratoire Dr. G. Bichsel SA, Interlaken, Switzerland) to prevent blood clotting overnight.

On the day of the experiment, cows were randomly allocated to 4 treatment groups (LPS, $\mathrm{n}=7$; LTA, $\mathrm{n}$ $=6$; LPS $+\mathrm{OT}, \mathrm{n}=7$; LTA $+\mathrm{OT}, \mathrm{n}=7$ ). Immediately following the morning milking, 2 quarters from each cow (one treatment, one control) were injected with the treatment by sterilizing each teat with gauze soaked in $70 \%$ ethanol and inserting a sterilized teat cannula. An upward massage of $15 \mathrm{~s}$ was performed immediately after injection to move the injection fluid into the parenchymal tissue. Injected quarters were randomly assigned for each cow to avoid sampling bias. Treatments were prepared as follows: $0.2 \mu \mathrm{g}$ of LPS (from $E$. coli serotype O26:B6, Sigma-Aldrich, St. Louis, MO) was diluted in $10 \mathrm{~mL}$ of $0.9 \%$ sterile saline; $20 \mu \mathrm{g}$ of LTA (from S. aureus, Sigma-Aldrich) was diluted in $10 \mathrm{~mL}$ of $0.9 \%$ sterile saline; control treatment was 10 $\mathrm{mL}$ of $0.9 \%$ sterile saline. Each cow served as its own control as each cow had one treatment and one control quarter. Quarters were considered independent for this study because previous research showed no differences in control quarters from cows that had an adjacent quarter challenged with LPS, LTA, or saline control (Wall et al., 2016). Time of injection was designated as time $0 \mathrm{~h}$. At $2 \mathrm{~h}$ postinjection, either $100 \mathrm{IU}$ of OT (10 $\mathrm{IU} / \mathrm{mL}$; Werner Stricker AG, Zollikofen, Switzerland) or $10 \mathrm{~mL}$ of $0.9 \%$ sterile saline (control) was injected through the jugular catheter. Dosages of endotoxin were chosen to induce similar SCC increases and were based on previous experiments from our group (Wall et al., 2016). Oxytocin dosage was chosen according to previous research by Allen (1990).

\section{Sampling Procedures: Temperature and Milk Samples}

The rectal temperature of each cow was measured immediately before injection and every hour until $8 \mathrm{~h}$ postchallenge. Milk samples were taken every $30 \mathrm{~min}$ 
between 0 and $8 \mathrm{~h}$. Milk samples were processed immediately for SCC, then stored at $-20^{\circ} \mathrm{C}$ until analysis.

\section{Laboratory Analyses}

Somatic Cell Count. Milk samples were processed for SCC using a DeLaval cell counter (DeLaval, Tumba, Sweden) according to the manufacturer's protocol. Samples were diluted 1:10 in commercially available milk if the cell count was $>3 \times 10^{6}$ because the detection limit for the cell counter is between $3 \times 10^{6}$ and $4 \times 10^{6}$ cells $/ \mathrm{mL}$. It was previously confirmed that the dilution of the samples did not have any falsifying matrix effects.

Lactate Dehydrogenase Activity. For LDH measurement, milk serum was obtained by a 2 -step process (centrifugation at $4,000 \times g$ for $15 \mathrm{~min}$ at $4^{\circ} \mathrm{C}$, then $14,000 \times g$ for $30 \mathrm{~min}$ at $4^{\circ} \mathrm{C}$ ). Lactate dehydrogenase activity was measured in milk serum by a commercial kit (AxonLab AG, Baden, Switzerland, cross-reacts with bovine LDH) using the COBAS MIRA automated analyzer (Roche Diagnostics, Basel, Switzerland) according to the manufacturer's instructions. The limit of detection was $0.01 \mathrm{mmol} / \mathrm{L}$.

Immunoglobulin G. The concentration of total $\operatorname{IgG}$ in milk was analyzed by ELISA using a bovine-specific commercial kit (Bethyl Laboratories, Montgomery, TX) according to the manufacturer's instructions with slight modifications (Lehmann et al., 2013). In brief, samples were diluted in wash buffer $(50 \mathrm{~m} M$ Tris, $0.14 \mathrm{M} \mathrm{NaCl}$, $0.05 \%$ Tween 20, adjusted to $\mathrm{pH} 8.0$ ) to ensure the samples were in range of the standards. The primary and secondary antibodies were diluted 1:200 and 1:100,000, respectively. The standard curve was adjusted to 400, 300, 150, 75, 37.5, 18.75, and $9.375(\mathrm{ng} / \mathrm{mL})$. Samples were blocked in blocking buffer containing $5 \%$ fish skin gelatin (Sigma-Aldrich, St. Louis, MO) diluted in double-distilled water. Absorbance measurements were read on the Synergy Mx plate reader (BioTek Instruments, Winooski, VT). The limit of detection was 9.375 $\mathrm{ng} / \mathrm{mL}$. The inter- and intraassay coefficients of variation were 5.61 and $7.89 \%$, respectively. All analyses were assayed in duplicate.

Serum Albumin. The concentration of SA in milk samples was analyzed by ELISA using a bovine-specific commercial kit (Bethyl Laboratories, Montgomery, TX) according to the manufacturer's instructions. Milk samples were diluted in wash buffer ( $50 \mathrm{~m} M$ Tris, $0.14 M \mathrm{NaCl}, 0.05 \%$ Tween 20, adjusted to $\mathrm{pH} 8.0$ ) to ensure the samples were in range of the standards. Absorbance measurements were read on the Synergy Mx plate reader (BioTek Instruments). The standard curve was $400,200,100,50,25,12.5,6.25(\mathrm{ng} / \mathrm{mL})$, and the limit of detection was $6.25 \mathrm{ng} / \mathrm{mL}$. The inter- and intra-assay coefficients of variation were 4.58 and $6.99 \%$, respectively. All analyses were assayed in duplicate.

\section{Statistical Analysis}

All results are presented as means \pm SEM. Statistical analysis of SCC (at a logarithmic scale, $\log _{10}$ ), IgG, SA, $\mathrm{LDH}$, and rectal temperature was performed using a mixed model ANOVA with the MIXED procedure of SAS (version 9.4; SAS Institute Inc., Cary, NC) with Tukey-Kramer adjustment. The model included time, treatment, and the interaction between both (time $\times$ treatment) as fixed effects and cow as the repeated subject. Values were considered significant when $P<0.05$.

\section{RESULTS}

\section{Rectal Temperature}

Rectal temperature in all cows ranged from 37.7 to $39.8^{\circ} \mathrm{C}$. No differences were found between treatment groups at any time point and temperature did not change during the experiment for any group (data not shown).

\section{Somatic Cell Count}

Somatic cell count was higher in quarters challenged with LPS and LTA than in control quarters beginning at $3 \mathrm{~h}$ and $3.5 \mathrm{~h}$ postchallenge until the end of experiment, and no statistical differences were found between LPS- and LTA-challenged quarters throughout the experiment (data not shown). Somatic cell count was higher in LPS+OT quarters than LPS quarters from $6 \mathrm{~h}$ until the end of the experiment (Figure 1A). The LTA+OT quarters had higher SCC than LTA quarters at $0,0.5,1.5$, and $2.5 \mathrm{~h}$ (Figure $1 \mathrm{~B}$ ). Control+OT quarters had higher SCC than control quarters at $4 \mathrm{~h}$ and then from $5 \mathrm{~h}$ until the end of the experiment (Figure $1 \mathrm{C})$.

Somatic cell count in LPS and LPS+OT quarters was elevated compared with time $0 \mathrm{~h}$ from $3 \mathrm{~h}$ until the end of the experiment. The LTA quarters had elevated SCC compared with time $0 \mathrm{~h}$ from $3.5 \mathrm{~h}$ until the end of the experiment, and LTA+OT quarters were elevated compared with time $0 \mathrm{~h}$ only at 6.5 and 7 h. Control+OT quarters had elevated SCC compared with time $0 \mathrm{~h}$ at $4 \mathrm{~h}$ then from $5.5 \mathrm{~h}$ until the end of experiment. No significant elevation occurred in SCC in the control quarters. 
A

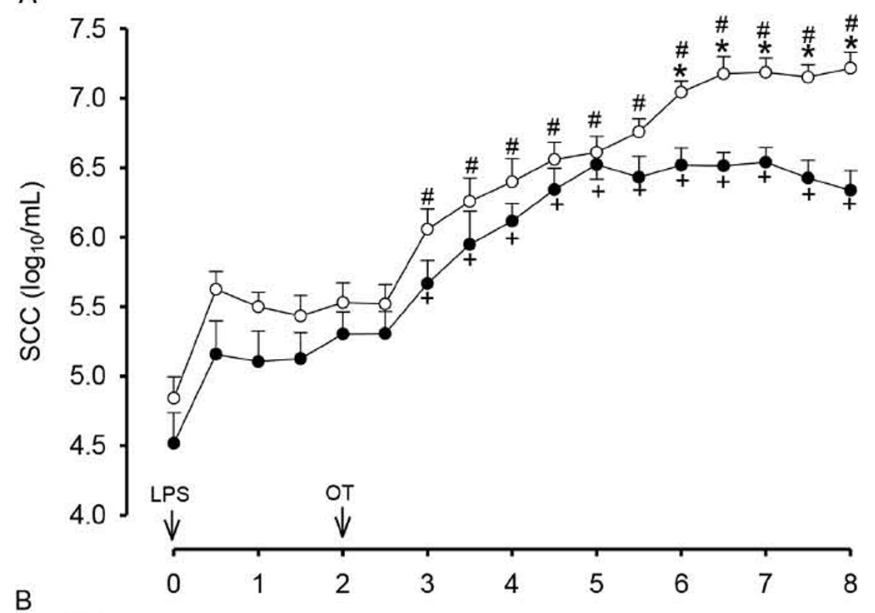

B
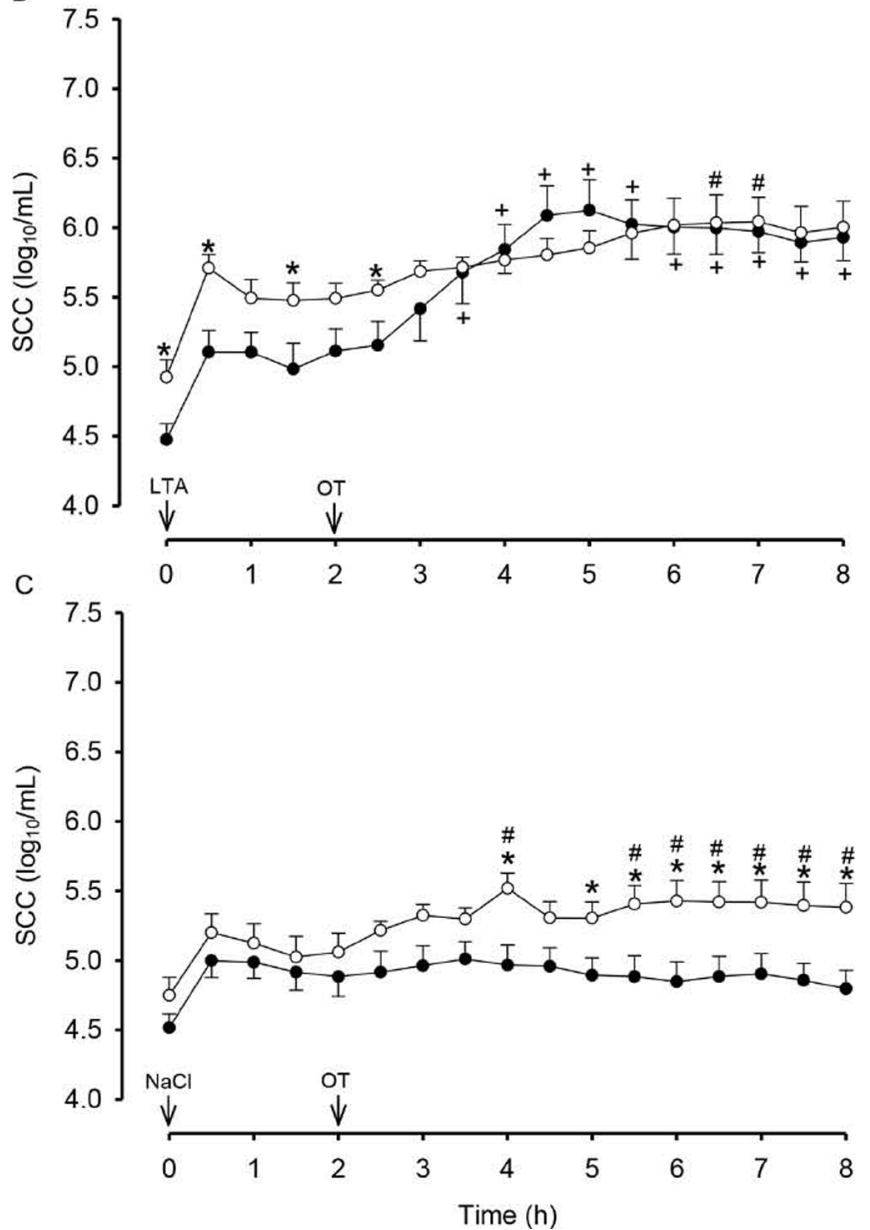

Figure 1. Somatic cell count (presented in log scale) in LPS and LPS+OT quarters (A), LTA and LTA+OT quarters (B), and control and control+OT (C). Data are presented as means \pm SEM. For graph A, mean SCC in LPS quarters, $\bigcirc$ mean SCC in LPS+OT quarters. For graph B, - mean SCC in LTA quarters, $\bigcirc$ mean SCC in LTA+OT quarters. For graph $\mathrm{C},-$ mean SCC in control quarters, $\mathrm{O}$ mean $\mathrm{SCC}$ in control+OT quarters. ${ }^{*}$ Indicates significance between groups. +Indicates significant elevation compared with time point 0 for LPS, LTA, or control. \#Indicates time point of significant elevation compared with time point 0 for $\mathrm{LPS}+\mathrm{OT}$, LTA $+\mathrm{OT}$, or control+OT. $\mathrm{LTA}=$ lipoteichoic acid, OT $=$ oxytocin .

\section{Immunoglobulin $G$}

Immunoglobulin $\mathrm{G}$ concentrations were higher in LPS quarters than LPS+OT quarters only at $2.5 \mathrm{~h}$, but were higher in LPS+OT quarters than LPS quarters from $6 \mathrm{~h}$ until the end of the experiment (Figure 2A).
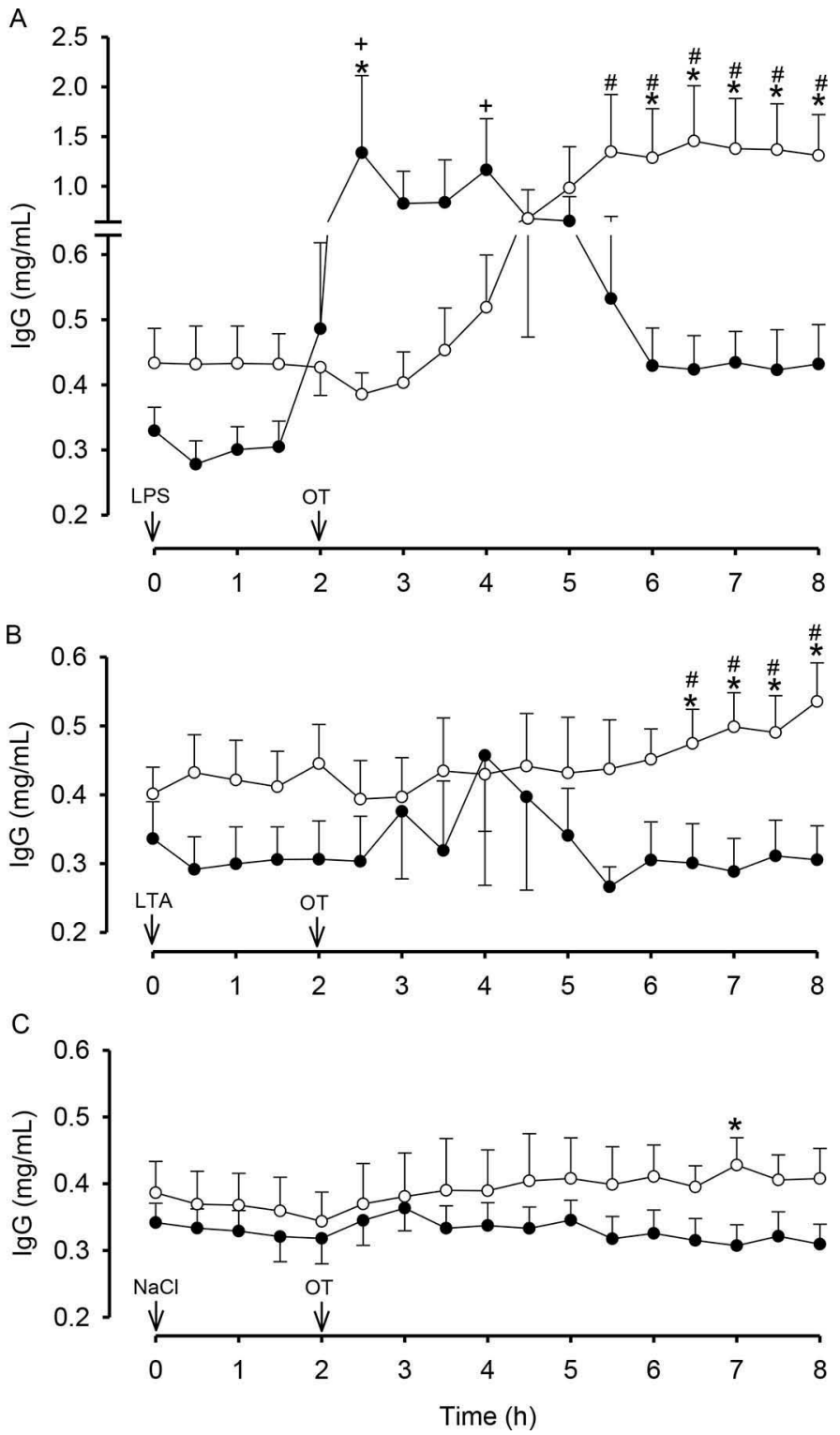

Figure 2. Immunoglobulin G concentration in LPS and LPS+OT quarters (A), LTA and LTA+OT quarters (B), and control and control+OT (C). Data are presented as means \pm SEM. For graph A, - mean SCC in LPS quarters, $\bigcirc$ mean SCC in LPS+OT quarters. For graph B, - mean SCC in LTA quarters, $\bigcirc$ mean SCC in LTA+OT quarters. For graph C, $\bullet$ mean SCC in control quarters, $\mathrm{O}$ mean SCC in control+OT quarters. *Indicates significance between groups. +Indicates significant elevation compared with time point 0 for LPS, LTA, or control. \#Indicates time point of significant elevation compared with time point 0 for LPS+OT, LTA+OT, or control+OT. $\mathrm{LTA}=$ lipoteichoic acid, OT $=$ oxytocin 
Immunoglobulin $\mathrm{G}$ concentrations were higher in the LTA+OT quarters compared with the LTA quarters from $6.5 \mathrm{~h}$ until the end of the experiment (Figure 2B). Immunoglobulin $\mathrm{G}$ concentrations were higher in the control+OT quarters only at $7 \mathrm{~h}$ (Figure 2C).

Immunoglobulin $\mathrm{G}$ concentrations were elevated compared with time $0 \mathrm{~h}$ in the LPS quarters only at 2.5 and $4 \mathrm{~h}$ and elevated in the LPS+OT quarters from 5.5 $\mathrm{h}$ until the end of the experiment. Quarters challenged with LTA+OT exhibited elevated IgG compared with time $0 \mathrm{~h}$ from $6.5 \mathrm{~h}$ until the end of the experiment, but there was no significant elevation of IgG compared with time $0 \mathrm{~h}$ in LTA quarters. There was no significant elevation of $\operatorname{IgG}$ compared with time $0 \mathrm{~h}$ in control quarters and control+OT quarters.

\section{Lactate Dehydrogenase}

Lactate dehydrogenase was higher in LPS+OT quarters than LPS quarters from 0 to $2 \mathrm{~h}$ and at 3, 3.5, 4.5, $6.5,7$, and $7.5 \mathrm{~h}$ (Figure 3A). The LTA+OT quarters had elevated LDH compared with LTA quarters from 2.5 to $3.5 \mathrm{~h}$ and from $6.5 \mathrm{~h}$ until the end of the experiment (Figure 3B). Control+OT quarters had higher $\mathrm{LDH}$ than control quarters at 1 and $1.5 \mathrm{~h}$ then from 2.5 $\mathrm{h}$ until the end of the experiment (Figure 3C).

The LPS and LPS+OT quarters had elevated LDH compared with time $0 \mathrm{~h}$ from 5 and $5.5 \mathrm{~h}$ until the end of the experiment. The LTA quarters were elevated compared with time $0 \mathrm{~h}$ only from 4 to $6 \mathrm{~h}$, and LTA+OT quarters were elevated from $2.5 \mathrm{~h}$ until the end of the experiment. Control+OT quarters had elevated $\mathrm{LDH}$ from $2.5 \mathrm{~h}$ until the end of the experiment. There was no elevation from time $0 \mathrm{~h}$ in the control quarters.

\section{Serum Albumin}

Serum albumin concentrations were higher in LPS+OT quarters compared with LPS quarters from 6 $\mathrm{h}$ until the end of the experiment (Figure 4A). Serum albumin concentrations were higher in LTA+OT quarters than LTA quarters at $1,1.5$, and 3.5 , and $5.5 \mathrm{~h}$, then from $6.5 \mathrm{~h}$ until the end of the experiment (Figure 4B). Serum albumin concentrations were higher in the control+OT quarters than the control quarters from $6.5 \mathrm{~h}$ until the end of the experiment (Figure 4C).

Quarters challenged with LPS had elevated SA concentrations compared with time $0 \mathrm{~h}$ at $2.5,3$, and $4 \mathrm{~h}$ and LPS+OT quarters had an elevation in SA from 5.5 $\mathrm{h}$ until the end of the experiment. Serum albumin concentrations were elevated from time $0 \mathrm{~h}$ in LTA+OT quarters at $5.5 \mathrm{~h}$ until the end of the experiment and there was no elevation compared with time $0 \mathrm{~h}$ in LTA

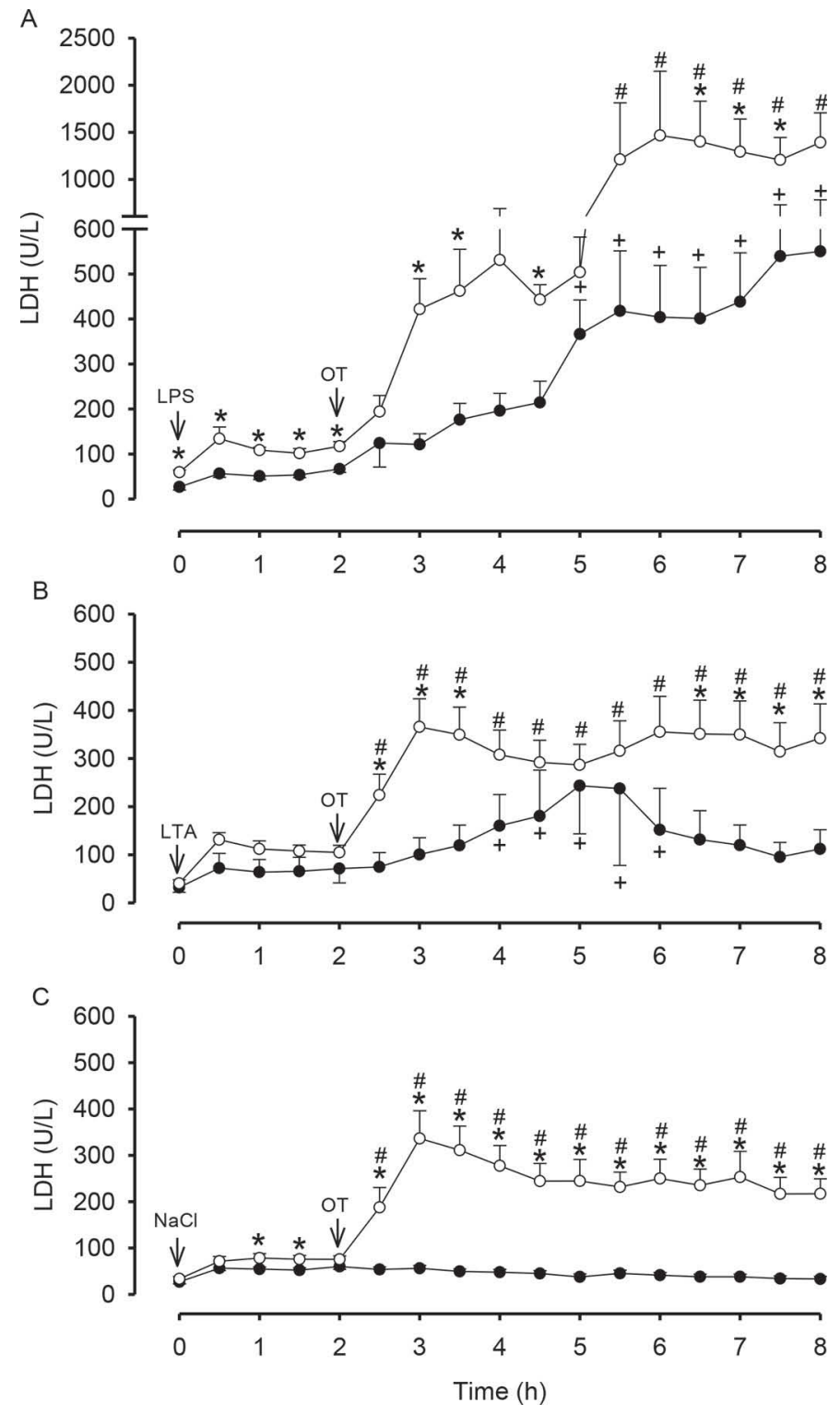

Figure 3. Lactate dehydrogenase (LDH) in LPS and LPS+OT quarters (A), LTA and LTA+OT quarters (B), and control and control+OT (C). Data are presented as means \pm SEM. For graph $\mathrm{A}$, - mean SCC in LPS quarters, $\bigcirc$ mean SCC in LPS+OT quarters. For graph B, - mean SCC in LTA quarters, $\bigcirc$ mean SCC in LTA+OT quarters. For graph C, mean SCC in control quarters, $\mathrm{O}$ mean SCC in control+OT quarters. *Indicates significance between groups. +Indicates significant elevation compared with time point 0 for LPS, LTA, or control. \#Indicates time point of significant elevation compared with time point 0 for $\mathrm{LPS}+\mathrm{OT}$, LTA+OT, or control+OT. $\mathrm{LTA}=$ lipoteichoic acid, $\mathrm{OT}=$ oxytocin .

quarters. Serum albumin concentrations were elevated compared with time $0 \mathrm{~h}$ in the control+OT quarters from $6 \mathrm{~h}$ until the end of the experiment. There was no elevation of SA from time $0 \mathrm{~h}$ in control quarters throughout the experiment. 


\section{DISCUSSION}

Bacteria invading the mammary gland can cause pathogen-specific differential permeability of the epithelial barrier (Wellnitz et al., 2016) and the differential

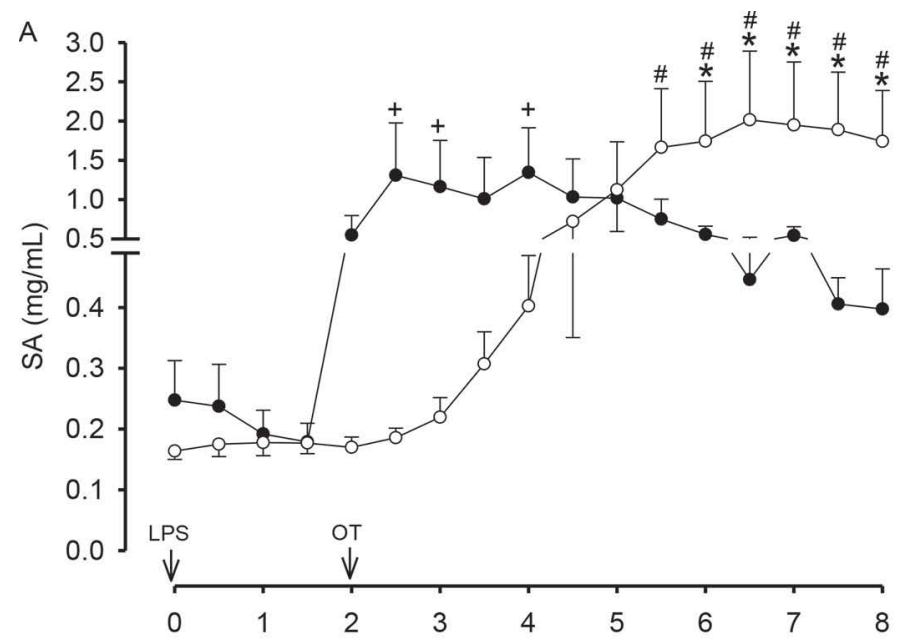

B
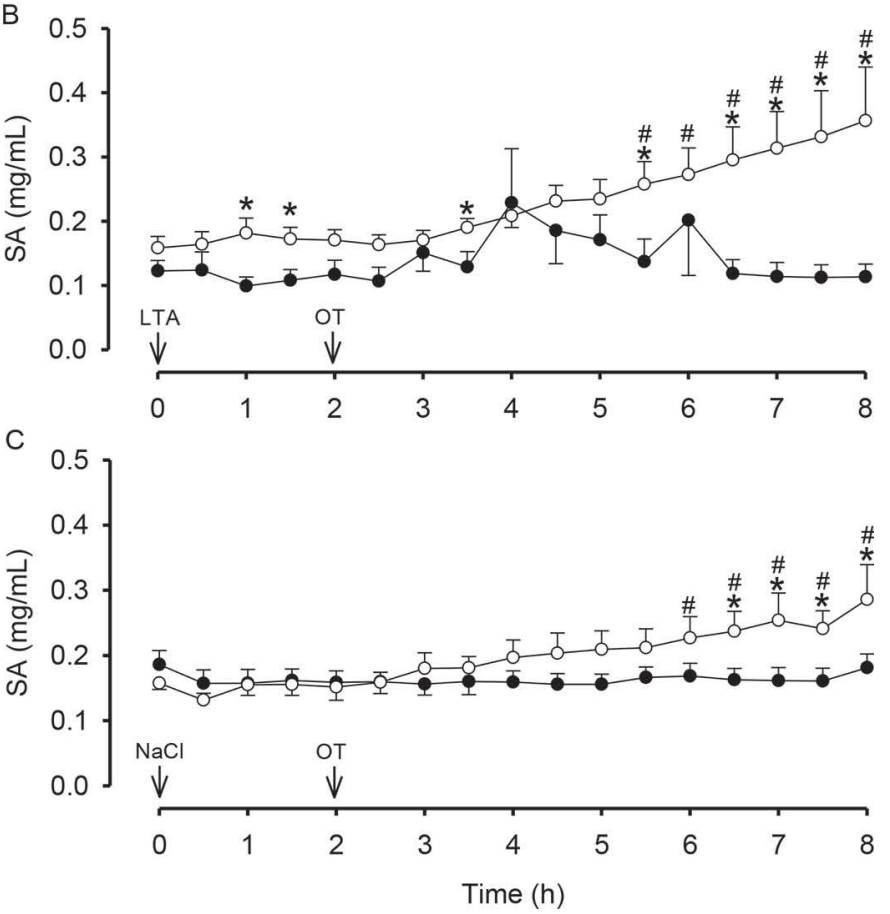

Figure 4. Serum albumin (SA) concentration in LPS and LPS+OT quarters (A), LTA and LTA+OT quarters (B), and control and control+OT (C). Data are presented as means \pm SEM. For graph A, - mean SCC in LPS quarters, $\bigcirc$ mean SCC in LPS+OT quarters. For graph B, - mean SCC in LTA quarters, $\bigcirc$ mean SCC in LTA+OT quarters. For graph C, mean SCC in control quarters, O mean SCC in control+OT quarters. *Indicates significance between groups. +Indicates significant elevation compared with time point 0 for LPS, LTA, or control. \#Indicates time point of significant elevation compared with time point 0 for $\mathrm{LPS}+\mathrm{OT}$, LTA+OT, or control+OT. $\mathrm{LTA}=$ lipoteichoic acid, OT $=$ oxytocin. transfer of blood components (Wellnitz and Bruckmaier, 2011). Pathogens like E. coli have a greater effect on the blood-milk barrier, and consequently, a larger transfer of blood proteins to milk in comparison to mastitis caused by S. aureus (Bannerman et al., 2004). Specifically, our group has previously shown that $\operatorname{IgG}$ is increased in the milk only in quarters challenged with LPS compared with quarters challenged with LTA at the same level of SCC increase (Wellnitz et al., 2013). The transfer of IgG is assumed to be of particular importance as it is the major opsonin for phagocytosis in the mammary gland if specific antibodies against the invading pathogen are present (Burton and Erskine, 2003).

In previous studies in our group, cell wall components LPS and LTA were used to mimic the inflammation during mastitis and the dosages of LPS and LTA were chosen to standardize the immune response based on a similar SCC increase. This allows for the quantitative comparison of additional factors (Wellnitz and Bruckmaier, 2011). This similar SCC increase was also accomplished in the current study. Relatively low doses of LPS and LTA were chosen to induce a moderate response in the mammary gland allowing for the optimal investigation of differences in blood-milk barrier permeability.

In the present study, to examine the effect of OT on the blood-milk barrier and the transfer of blood components, several proteins that can be used as markers for barrier permeability were measured. Results showed that OT increased the concentration of IgG in LPS and LTA treated quarters compared with cows that were not treated with OT. However, there was only a single time point where $\operatorname{IgG}$ concentrations were increased in response to OT injection in the control quarters. Oxytocin increased SA concentration and $\mathrm{LDH}$ in quarters treated with LPS and LTA, but also in control quarters. Both SA and LDH have no known immune function in the mammary gland; however, both proteins undergo paracellular transport when the blood-milk barrier is leaky (Stelwagen et al., 1994; Lehmann et al., 2013; Wall et al., 2015). Lactate dehydrogenase has been proposed as a good indicator of IgG concentration in milk during mastitis (Lehmann et al., 2013) as LDH and IgG are typically both increased during infections and due to the practicality of this measurement on farm. The increase in concentrations of IgG, SA, and $\mathrm{LDH}$, in both challenged and unchallenged quarters, demonstrates that OT can increase permeability of the mammary epithelial barrier. Interestingly, it was observed that OT induced an increase in IgG concentration in only LPS and LTA quarters, but not control quarters. Nevertheless, IgG may need a stimulus, such as a mas- 
titis-causing pathogen or immunostimulatory protein, to be transferred to the milk. Notably, although OT caused an increased transfer of blood proteins in both LTA and control quarters, they still did not reach the levels of quarters treated only with LPS.

The pattern of increase in IgG and SA in LPSchallenged quarters was different between cows that were treated with OT compared with those that were not. In LPS-treated quarters without OT administration, significant increases occurred between 2 and $4 \mathrm{~h}$, whereas cows that received the OT treatment did not exhibit increases until around $5 \mathrm{~h}$ postchallenge. These differences could be due to the milk ejection induced by the OT administration at $2 \mathrm{~h}$. It was previously shown that concentrations of SA and $\operatorname{IgG}$ decrease after just $120 \mathrm{~s}$ of first contact with the udder; therefore, it is likely that SA and $\operatorname{IgG}$ were diluted due to alveolar milk ejection (Lehmann et al., 2015).

The intermittent increases in SA and IgG in the LPS quarters without OT administration between 2 and 4 $\mathrm{h}$ could also be due to previous exposure to mastitis pathogens. Records for previous mastitis or vaccination against mastitis-causing pathogens of the cows were not available. This could have influenced the immune competency of the cows' mammary glands, as cows can have an increased immune response to antigens after first contact (Rainard and Paape, 1997). In addition, the intermittent increases could be due to the low dose of LPS and individual variation between cows. Individual susceptibility to low doses has been previously shown in the response of bovine dermal fibroblasts during experimentally induced E. coli mastitis (Kandasamy et al., 2011).

Lipopolysaccharide typically induces a pronounced SCC increase (Wellnitz and Bruckmaier, 2011; Wellnitz et al., 2015), but in the present study, OT induced an additional increase in SCC between 6 and 8 h. Oxytocin also induced an SCC increase in control quarters; however, this increase was not seen in LTAtreated quarters. The baseline SCC of the LTA+OT quarters before treatment was already significantly higher than LTA quarters at the beginning of the experiment, which could have masked any effects that the OT treatment would have on the SCC. Although quarters from cows in both groups were considered healthy, some cows in the LTA group had very low SCC. Increased SCC in the LPS and control quarters could indicate increased permeability of the bloodmilk barrier by OT, though migrating immune cells can enter the milk following several different pathways including paracellular or transcellular transport (McDonald and Kubes, 2011) or migrating cells can push mammary epithelial cells off the basement membrane creating a gap where more cells can enter (Akers and Nickerson, 2011). The increase in SCC observed in the control quarters is consistent with Allen (1990) who also observed an increase in SCC when cows were treated with $100 \mathrm{IU}$ of $\mathrm{OT}$, indicating an opening of the blood-milk barrier.

Oxytocin could likely be used in mastitis cases, such as subclinical infections, where there is lessened or no transfer of IgG. Mastitis caused by S. aureus is usually subclinical and can become chronic (Sutra and Poutrel, 1994). Currently, S. aureus mastitis is difficult to treat as cows infected with this bacterium do not respond well to antibiotic therapies and there is typically only a 35\% cure rate (Pyörälä and Pyörälä, 1997; Sol et al., 1997). This could be due to the fact that Staphylococcus aureus has evolved mechanisms to evade the host immune system, such as invading host immune cells and mammary epithelial cells and persisting as an intracellular pathogen (Hébert et al., 2000). In addition, this bacterium can cause abscesses and scar tissue in the mammary gland that block the antibiotic from reaching the pathogen (Nickerson, 1993). However, inducing the opening of the blood-milk barrier and in turn, a transfer of IgG, could likely result in a better cure rate for these infections.

The effects of an increased transfer of immune proteins and PMN in clinical mastitis cases, due to treatments such as OT, is not yet known, but it can be speculated that it could cause additional damage to the mammary gland due to the bacterial killing mechanisms of PMN (Wellnitz and Bruckmaier, 2012). Additionally, the binding capability of IgG to pathogens in the mammary gland needs to be examined to see if a greater transfer of IgG to the milk is an effective treatment for mastitis.

Oxytocin is known to decrease the integrity of the blood-milk barrier (Allen, 1990), but the mechanism is undetermined. It is likely that OT opens the barrier by compromising the integrity of the mammary tight junctions (Stelwagen and Singh, 2014) that are part of the junctional complexes between epithelial cells (Tsukita et al., 2001). In the present study, it was observed that LDH was significantly increased $30 \mathrm{~min}$ after OT injection in control and LTA-treated quarters. This was different compared with other parameters. Lactate dehydrogenase is mainly transferred from blood to milk; however, some LDH can be released by damaged cells (Bogin et al., 1977). This increase of LDH at $2.5 \mathrm{~h}$ after the start of experiment (i.e., $30 \mathrm{~min}$ after OT injection) could indicate that the high dose of OT induces a further opening of tight junctions or these results could indicate the OT is causing some damage to mammary epithelial cells. 
Oxytocin has been described as a mastitis therapy in several papers; however, this is the first study examining the permeability of the blood-milk barrier and the transfer of blood components under simulated mastitis conditions. Knight et al. (2000) experimentally infected quarters with a low virulence strain of $S$. aureus and observed that intramuscular OT could significantly reduce the amount of bacteria and OT did not differ in efficacy from an antibiotic. Furthermore, Guterbock et al. (1993), who also used intramuscular OT to treat naturally occurring mastitis, showed no differences in clinical or bacterial cure rates between antibiotic treatment and OT treatment. Knight et al. (2000) hypothesized that OT is effective as a mastitis therapy by inducing milk ejection that promotes the emptying of the udder and in turn the removal of the pathogen. However, it is possible that the increased $\operatorname{IgG}$ in the present study could additionally explain the efficacy of the OT treatment in both experimentally induced and naturally occurring mastitis.

\section{CONCLUSIONS}

The results of the present study show that supraphysiological OT can open the blood-milk barrier and even enhance the opening that occurs during LPS-induced mastitis. These results also confirm the hypothesis that OT can induce a greater transfer of blood components to milk. Although SA and LDH have no known immune function in the mammary gland, the increased concentration of IgG shows that OT could have implications in increasing the cure rate of subclinical infections if antibodies against the mastitis-causing pathogen are available in the blood (i.e., after vaccination). In addition, further studies on the binding of IgG to pathogens in the mammary gland are also needed to support this hypothesis. Oxytocin treatment is likely most effective when there is little or no transfer of IgG, such as in subclinical mastitis cases. Therefore, the mastitis-causing pathogen should be considered when using OT as a treatment.

\section{ACKNOWLEDGMENTS}

The authors thank Yolande Zbinden, Anna-Lena Neuheuser, and Denisa Dan (Veterinary Physiology, Vetsuisse Faculty University of Bern, Switzerland) for technical assistance. We are grateful to Kerst Stelwagen (SciLactis Ltd., New Zealand) for participating in discussions about experimental design and treatments. This study was supported by the Swiss National Science Foundation (grant no. 149460).

\section{REFERENCES}

Akers, R. M., and S. C. Nickerson. 2011. Mastitis and its impact on structure and function in the ruminant mammary gland. J. Mammary Gland Biol. Neoplasia 16:275-289.

Allen, J. C. 1990. Milk synthesis and secretion rates in cows with milk composition changed by oxytocin. J. Dairy Sci. 73:975-984.

Bannerman, D. D., M. J. Paape, J. W. Lee, X. Zhao, J. C. Hope, and P. Rainard. 2004. Escherichia coli and Staphylococcus aureus elicit differential innate immune responses following intramammary infection. Clin. Diagn. Lab. Immunol. 11:463-472.

Bogin, E., G. Ziv, J. Avidar, B. Rivetz, S. Gordin, and A. Saran. 1977. Distribution of lactate dehydrogenase isoenzymes in normal and inflamed bovine udders and milk. Res. Vet. Sci. 22:198-200.

Burton, J. L., and R. J. Erskine. 2003. Immunity and mastitis. Some new ideas for an old disease. Vet. Clin. North Am. Food Anim. Pract. 19:1-45.

Guterbock, W. M., A. L. Van Eenennaam, R. J. Anderson, I. A. Gardner, J. S. Cullor, and C. A. Holmberg. 1993. Efficacy of intramammary antibiotic therapy for treatment of clinical mastitis caused by environmental pathogens. J. Dairy Sci. 76:3437-3444.

Hébert, A., K. Sayasith, S. Sénéchal, P. Dubreuil, and J. Lagacé. 2000. Demonstration of intracellular Staphylococcus aureus in bovine mastitis alveolar cells and macrophages isolated from naturally infected cow milk. FEMS Microbiol. Lett. 193:57-62.

Hogan, J. S., R. N. Gonzales, R. J. Harmon, S. C. Nickerson, S. P. Oliver, J. W. Pankey, and K. L. Smith. 1999. Laboratory Handbook on Bovine Mastitis. Rev. ed. National Mastitis Council, Madison, WI.

Kandasamy, S., B. B. Green, A. L. Benjamin, and D. E. Kerr. 2011. Between-cow variation in dermal fibroblast response to lipopolysaccharide reflected in resolution of inflammation during Escherichia coli mastitis. J. Dairy Sci. 94:5963-5975.

Knight, C. H., J. L. Fitzpatrick, D. N. Logue, and D. J. Platt. 2000. Efficacy of two non-antibiotic therapies, oxytocin and topical liniment, against bovine staphylococcal mastitis. Vet. Rec. 146:311316.

Lehmann, M., S. K. Wall, O. Wellnitz, and R. M. Bruckmaier. 2015. Changes in milk L-lactate, lactate dehydrogenase, serum albumin, and IgG during milk ejection and their association with somatic cell count. J. Dairy Res. 82:129-134.

Lehmann, M., O. Wellnitz, and R. M. Bruckmaier. 2013. Concomitant lipopolysaccharide-induced transfer of blood-derived components including immunoglobulins into milk. J. Dairy Sci. 96:889-896.

McDonald, B., and P. Kubes. 2011. Cellular and molecular choreography of neutrophil recruitment to sites of sterile inflammation. J. Mol. Med. 89:1079-1088.

Nguyen, D. A., and M. C. Neville. 1998. Tight junction regulation in the mammary gland. J. Mammary Gland Biol. Neoplasia 3:233246.

Nickerson, S. C. 1993. Eliminating chronic Staphylococcus aureus mastitis. Vet. Med. 88:375-381.

Pyörälä, S., and E. Pyörälä. 1997. Accuracy of methods using somatic cell count and N-acetyl-beta-D-glucosaminidase activity in milk to assess the bacteriological cure of bovine clinical mastitis. J. Dairy Sci. 80:2820-2825.

Rainard, P., and M. J. Paape. 1997. Sensitization of the bovine mammary gland to Escherichia coli endotoxin. Vet. Res. 28:231-238.

Sol, J., O. C. Sampimon, J. J. Snoep, and Y. H. Schukken. 1997. Factors associated with bacteriological cure during lactation after therapy for subclinical mastitis caused by Staphylococcus aureus. J. Dairy Sci. 80:2803-2808.

Stelwagen, K., I. Politis, J. H. White, B. Zavizion, C. G. Prosser, S. R. Davis, and V. C. Farr. 1994. Effect of milking frequency and somatotropin on the activity of plasminogen activator, plasminogen, and plasmin in bovine milk. J. Dairy Sci. 77:3577-3583.

Stelwagen, K., and K. Singh. 2014. The role of tight junctions in the mammary gland. J. Mammary Gland Biol. Neoplasia 19:131-138. 
Sutra, L., and B. Poutrel. 1994. Virulence factors involved in the pathogenesis of bovine intramammary infections due to Staphylococcus aureus. J. Med. Microbiol. 40:79-89.

Tsukita, S., M. Furuse, and M. Itoh. 2001. Multifunctional strands in tight junctions. Nat. Rev. Mol. Cell Biol. 2:285-293.

Wall, S. K., J. J. Gross, E. C. Kessler, K. Villez, and R. M. Bruckmaier. 2015. Blood-derived proteins in milk at start of lactation: Indicators of active or passive transfer. J. Dairy Sci. 98:7748-7756.

Wall, S. K., L. E. Hernández-Castellano, A. Ahmadpour, R. M. Bruckmaier, and O. Wellnitz. 2016. Differential glucocorticoid-induced closure of the blood-milk barrier during lipopolysaccharide- and lipoteichoic acid-induced mastitis in dairy cows. J. Dairy Sci. 99:7544-7553. http://dx.doi.org/10.3168/jds.2016-11093.

Wellnitz, O., E. T. Arnold, M. Lehmann, and R. M. Bruckmaier. 2013. Short communication: Differential immunoglobulin transfer during mastitis challenge by pathogen-specific components. J. Dairy Sci. $96: 1681-1684$.
Wellnitz, O., and R. M. Bruckmaier. 2011. Lipopolysaccharide and lipoteichoic acid induce different immune responses in the bovine mammary gland. J. Dairy Sci. 94:5405-5412.

Wellnitz, O., and R. M. Bruckmaier. 2012. The innate immune response of the bovine mammary gland to bacterial infection. Vet. J. 192:148-152.

Wellnitz, O., C. Zbinden, X. Huang, and R. M. Bruckmaier. 2016. Short communication: Differential loss of bovine mammary epithelial barrier integrity in response to lipopolysaccharide and lipoteichoic acid. J. Dairy Sci. 99:4851-4856.

Wellnitz, O., C. Zbinden, J. Lüttgenau, H. Bollwein, and R. M. Bruckmaier. 2015. Different chronological patterns of appearance of blood derived milk components during mastitis indicate different mechanisms of transfer from blood into milk. J. Dairy Res. $82: 322-327$ 